\title{
Association Of Cigarette Smoking With Anxiety, Depression, And Suicidal Ideation Among Brazilian Adolescents
}

This article was published in the following Dove Press journal: Neuropsychiatric Disease and Treatment

Fátima Martinez Slomp ${ }^{1,2}$ Tiago S Bara ${ }^{1,3}$ Gledson Luiz Picharski ${ }^{1,3}$ Mara L Cordeiro (iD) ${ }^{1-4}$

'Faculdades Pequeno Príncipe, Curitiba, Brazil; ${ }^{2}$ Guarapuava Centre-West University, Guarapuava, Brazil; ${ }^{3}$ Research Institute Pelé Pequeno Príncipe, Curitiba, Brazil; ${ }^{4}$ Department of Psychiatry and Biobehavioral Sciences, David Geffen School of Medicine, Semel Institute for Neuroscience and Human Behavior, University of California Los Angeles, Los Angeles, CA, USA
Correspondence: Mara L Cordeiro Av. Silva Jardim 1632, Curitiba, PR, Brazil 80250- 120

Tel +55 4l 3310-I035

Email mcordeiro@mednet.ucla.edu
Background: Several studies worldwide have pointed to depression and anxiety symptoms as being related to adolescent smoking. The aim of this study was to investigate, the potential link of cigarette smoking with depression, anxiety, and suicidal ideation and the influence of gender on these relationships in Brazilian adolescents.

Methods: Associations of smoking with Children Depressive Inventory version 2 (CDI2) scores, Hamilton Anxiety Scale (HAM-A) scores, and poor school performance (i.e., grade retention) were examined in 988 Brazilian students (age range, 11-17 years) enrolled in 82 public and private schools. Logistic regression modeling was employed and the resultant odds ratios (ORs) are reported with 95\% CIs.

Results: Of 988 participants, 240 (24.3\%) were smokers. Mean ( \pm standard error) HAM-A scores were higher for smokers $(21.1 \pm 9.7)$ than nonsmokers $(15.4 \pm 8.6 ; p<0.0001)$. Relative to nonsmokers, smokers had higher total CDI2 scores $(p=0.033)$, and higher scores for the CDI2 domains of Emotional Problems $(p=0.023)$, Negative Self-esteem $(p<0.001)$, and Functional Problems $(p=0.046)$. Suicidal ideation was common among smokers with depressive symptoms $(54.2 \%)$. Smoking was associated with being held back three grades $(p<0.001)$. Female smokers were more likely to report suicidal ideation than male smokers $(p=0.020)$. Logistic regression modeling revealed significant associations of suicidal ideation with being female (OR, 1.81; 95\% CI, 1.38-2.37), being a female smoker (OR, 2.05; 95\% CI, 1.51-2.80), and having a HAM-A score $>16$ (OR, 2.18; 95\% CI, 1.66-2.86).

Conclusion: Smoking was found to be associated with anxiety symptoms, depressive symptoms, and poor school performance in Brazilian adolescents; and female smokers reported more suicidal ideation than male smokers.

Keywords: smoking, adolescence, depression, anxiety, suicide, school performance

\section{Introduction}

Adolescence is a vulnerable period of life, not only because of the series of adjustments involved in the transition from childhood to adulthood, but also because it is a time when mental health problems are prone to emerge, perhaps due to an immature limbic system and prefrontal cortex. ${ }^{1,2}$ Indeed, the age of onset of most severe psychiatric disorders is during adolescence. ${ }^{1}$ Developmentally, the adolescent brain and body undergo rapid changes, including the establishment of new neuronal connections based on a cascade of new experiences and dramatic hormonal changes that may produce a period of vulnerability to psychiatric disorders. ${ }^{3}$ Moreover, adolescents may cope with new stresses by developing 
harmful habits and risky behaviors, including tobacco cigarette smoking (referred to as simply smoking from here forward). ${ }^{4,5}$ There is a strong association between smoking and psychiatric disorders, though the nature of this association is not well understood.

Low self-esteem in adolescence has been identified as a predictive factor of smoking in adulthood. ${ }^{6}$ Notwithstanding, additional factors may motivate adolescents to smoke such as curiosity, peer (group or close friend) imitation, having smoking parents, ${ }^{6,7}$ and poor academic performance. ${ }^{8}$ In a longitudinal study, Hill and colleagues found that several familial factors may influence the onset of daily smoking in adolescents, including poverty, parental smoking, and a lack of rules and monitoring. ${ }^{9}$

Tobacco consumption has been associated with a number of psychopathological conditions in recent decades, including depression, anxiety, and attention-deficit/hyperactivity disorder. ${ }^{10-12}$ Half of the studies analyzed in Fluharty et al.'s recent systematic review reported that baseline depression or anxiety was associated with starting to smoke, increased smoking, or the transition from daily smoking to dependence. ${ }^{9}$ Tobacco use has a particularly strong association with depression symptomatology, and it has been suggested that greater tobacco and other drug use among youth with anxiety and depression may be attributed to mood elevating effects. ${ }^{12-14}$ Smoking in adolescent boys in particular has been associated with anxiousness or depression related to feelings of isolation and dissatisfaction with life. ${ }^{11,12}$

Most studies examining these issues have been conducted in developed countries. To date, no study has investigated smoking, psychopathology, and the role of gender in suicidal ideation in Brazilian adolescents. ${ }^{6,7,13-15}$ However, a recent systematic review of substance use and suicidal ideation in low- and middle-income countries demonstrated a consistent positive association between suicidal behavior and pathological tobacco use. ${ }^{16}$ Studies examining smoking in Brazilian adolescents have been limited to documenting adolescent smoking prevalence and nicotine dependence, with limited analyses of psychosocial factor relationships with smoking. ${ }^{13,17-19}$ In 2007 , Pinto et $\mathrm{al}^{20}$ found that $11 \%$ of a surveyed population of 1,520 teens described themselves as frequent smokers and further found that smoking was associated with social contacts with smokers, curiosity, and poor/mediocre academic performance. In a 2012 systematic review of tobacco and alcohol use among Brazilian adolescents, Barbosa Filho et $\mathrm{al}^{19}$ found a mean prevalence of current tobacco use among adolescents of 9.3\% (range,
2.4-22.0\%), which the authors described as alarming. Subsequently, in a 2013 study of 574 10- to 19-year-olds, Arrais-Ribeiro et $\mathrm{al}^{21}$ reported a smoking prevalence of $3.3 \%$ and found that smoking was associated with delays in schooling, alcohol use, and frequent alcohol use. In a study of 2,014 teens published in 2014, Bonilha et $\mathrm{al}^{7}$ found a smoking prevalence of $12.1 \%$ and found that smoking was associated with having friends who smoke, use of alcohol, use of illicit drugs, and being held back a grade in school. In a cross-sectional epidemiological study, also published in 2014, Menezes et $\mathrm{al}^{22}$ found that being $\geq 15$ years old and having friends who smoke were associated with greater likelihood of being a smoker.

Studies with adults investigating the link between psychopathology and smoking in Brazil may provide hints regarding possible analogous links in adolescents. ${ }^{23,24}$ Lopes and colleagues ${ }^{23}$ identified a $59 \%$ prevalence of nicotine dependence in a cohort of 262 psychiatric outpatients with anxiety or depressive disorder, but this prevalence rate did not differ significantly from the control group or the general population. ${ }^{23}$ However, in the crosssectional study of 182 adults in the process of quitting smoking, Pawlina and colleagues ${ }^{24}$ observed an association between nicotine dependence and greater severity of depression.

Although the public health burdens of tobacco-related disease and mental disorders appear to be linked, ${ }^{25}$ the cause-versus-effect relationship is difficult to clarify given the complex molecular effects of nicotine on the brain. Some studies ${ }^{26,27}$ have suggested that depressive and anxiety symptoms were associated with smoking initiation. Conversely, other recent studies have indicated that smoking may contribute to the development of these conditions. ${ }^{14,28}$ Furthermore, several studies have shown a link between smoking and suicide risk. ${ }^{29,30}$ Notably, in a logistic regression modeling study, Hallfors and colleagues found that being a smoker was a strong independent predictor of suicidal ideation. ${ }^{6}$ Because a female gender bias for internalizing behavioral symptoms (e.g. depression, anxiety/intense worry, somatic symptoms) is well documented in adolescents, ${ }^{31}$ we investigated whether this bias would be reflected in our findings and if so, if there would be any relationship to tobacco use.

The primary aims of the present study were two-fold. First, we examined potential links between smoking and psychopathological factors, including depressiveness, anxiety, and suicidal ideation, in Brazilian adolescents. Second, we examined whether such links may be affected 
by gender because the influence of gender on psychological problems, and risk of self-harm in particular, may have important clinical implications regarding case analysis and intervention efforts in girls versus in boys. We tested the hypothesis that female smokers may be at an elevated risk for depressiveness, anxiety, suicidal ideation.

\section{Materials And Methods Study Design And Sample}

This cross-sectional study was carried out with 988 students (age, 11-17 years, both sexes) enrolled in 82 schools in the city of Guarapuava, Paraná, Brazil. In the Brazilian education system, schooling (before college) encompasses ensino fundamental (grade years 1 to 9 , age range 6 14 years) and ensino médio (grade years 10 to 12 , age range $15 \sim 18$ ). Hence, the former is similar to elementary plus middle/junior high school in the USA, and the latter is similar to high school in the USA. Students are mandated to attend school (public or private) from age 6 to age 17 . Thus, we recruited students from Ensino fundamental and ensino médio schools. School principals and families of enrolled students were invited to participate voluntarily (without pay) following a presentation of the project aims and procedures. Of 1,015 families who volunteered to participate in this study, 988 completed the data collection process between July of 2014 and December of 2015; the remaining 27 were excluded for incomplete participation. A study population flowchart is shown in Figure 1.

A power analysis was conducted in which a sample size calculation for ratio was determined based on the central limit theorem, with simple random sampling. The power analysis indicated that we should include 989 adolescents with a $95 \%$ confidence level and a $3 \%$ margin of

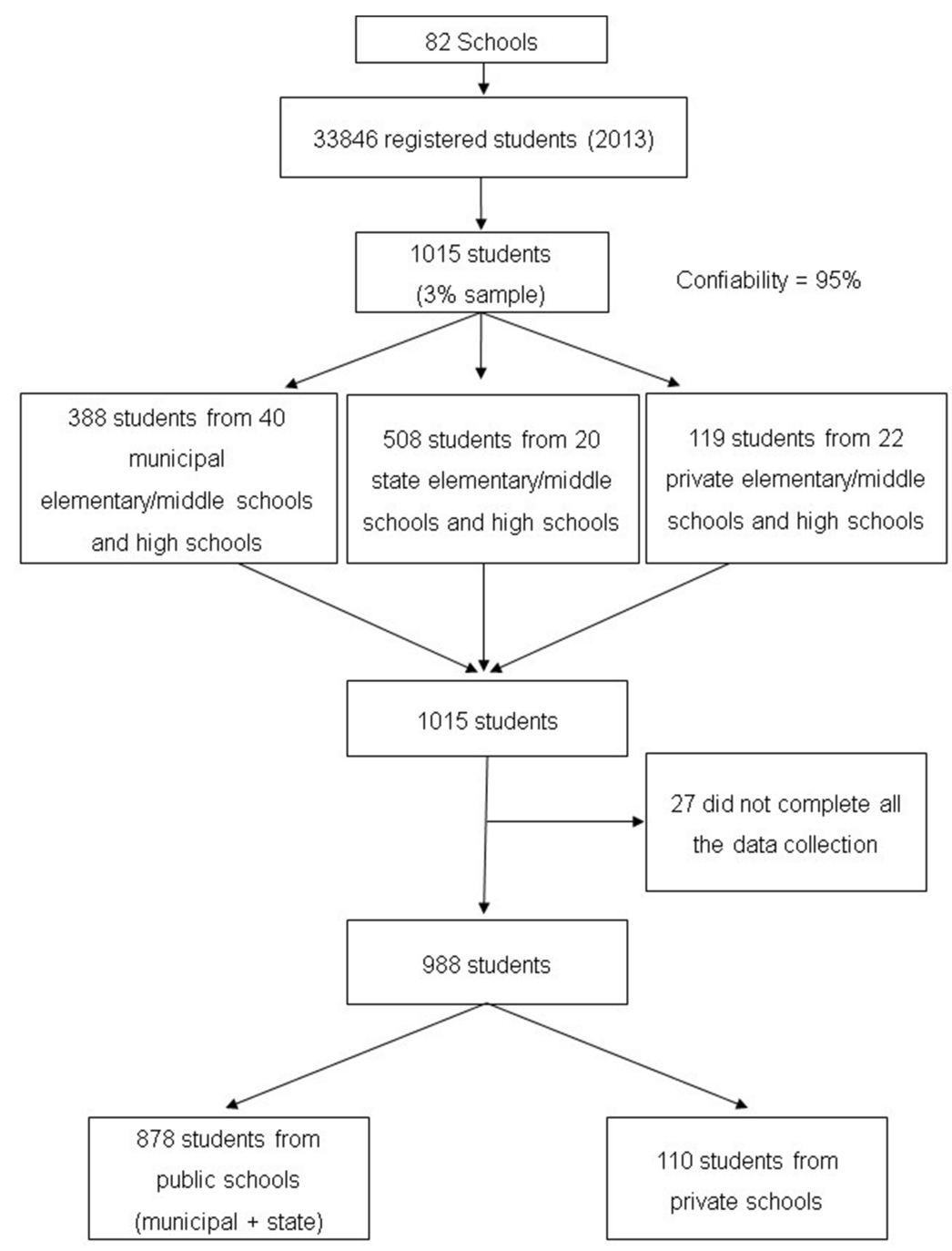

Figure I Study population flowchart. 
error. Thus, initially, 1,015 students (from a source population of 33,846 students) were enrolled from 82 secondary schools in the city of Guarapuava.

All aspects of this research were approved by the Research Ethics Committee on Human Research at Faculdades Pequeno Príncipe (protocol no. 561.735). Written consent was obtained from the participants and their parents before the study began.

\section{Data Collection}

The assessment instruments were administered by a field investigator (FS) on school campuses between July 1st, 2014 and December 30th, 2015.

\section{Sociodemographics}

Each participant completed an overall profile questionnaire and his or her parent completed a sociodemographic questionnaire. Both included items about the student participant's grade in school (Brazilian classification), school shift, academic delays, the presence of smokers at home, the presence of diseases, and drug/alcohol addictions (type and duration). Socioeconomic level (A-E), parent education, and occupation were classified according to the 2012 Associação Brasileira de Empresas de Pesquisa rubric. The adolescent profile questionnaire took about $10 \mathrm{~min}$ to complete, and the parent sociodemographic questionnaire took about $10 \mathrm{~min}$ to complete. Participants were categorized as smokers if they smoked at least 6 cigarettes/day in the past 12 months. Otherwise, there were classified as non-smokers.

\section{Fargerström Self-Report Test Of Nicotine Dependence (FTND)}

The FTND is a self-report questionnaire used for assessing the intensity of physical addiction to nicotine. It consists of six nicotine dependence questions with a total score range of $0-10$, wherein higher scores reflect greater dependence. ${ }^{32}$ The results were interpreted as follows: very low dependence (1-2 points, level $1 / 2$ ), low to moderate dependence (3-4 points, level 3 ), moderate/high dependence (5-7 points, level 4), and very high dependence ( $\geq 8$ points, level 5 ). This instrument was adapted to Brazilian Portuguese by Carmo and Pueyo (2002) with a Cronbach's alpha of $0.64 .{ }^{33}$ The FTND took about $3 \mathrm{~min}$ to complete.

\section{Children's Depression Inventory Version 2 (CDI2)}

The CDI2 self-report module, is a questionnaire that asks respondents to reflect on their depressive symptoms in the preceding 2 weeks. ${ }^{34}$ It encompasses two major domains, each of which is composed of two subscales as well as a critical item outside of these domains that asks explicitly about suicidal ideation. The first major domain, namely emotional problems, is composed of the negative mood and negative self-esteem subscales. The second major domain, namely functional issues, is composed of the ineffectiveness and personal problems subscales. The Brazilian version of the original version of this instrument, the CDI was translated, adapted and validated, and has adequate psychometric properties (Cronbach's alpha $=0.81){ }^{35}$ The definitive difference between the original and the second versions of this instrument is that the CDI2 allows raw scores be converted into $\mathrm{T}$ scores in analytical software, such that the mean raw score becomes a $\mathrm{T}$ score of 50 with a standard deviation of 10 . T scores were graded as follows: $<40$, below average; $40-59$, average; $60-64$, above average; 65-69, high; and $\geq 70$, very high. The CDI2 took about 10 min to complete.

Notably, we administered the aforementioned critical item of the CDI2 (item 8), which asks about suicidal ideation explicitly and is not part of the aforementioned domains. For this query, the participant was prompted to choose one of the following three responses: a) I do not think about killing myself; b) I think about killing myself, but would not do it; or c) I want to kill myself. The point value associated with responses $\mathrm{a}, \mathrm{b}$, and $\mathrm{c}$ were 0,1 , and 2 , respectively. Participants who had scores of 1 or 2 on item 8 were classified as having suicidal ideation. Those who had a score of 0 were classified as not having suicidal ideation. The item 8 responses were analyzed with respect to both smoking habits and gender.

\section{Hamilton Anxiety Rating Scale (HAM-A)}

The HAM-A assesses the degree of emotional (anxious mood, tension, fears) and somatic (muscle, sensory and gastrointestinal) symptoms related to anxiety. ${ }^{36}$ It has a score range of $0-56$, with scores $<12$ being considered normal (without troublesome anxiety). HAM-A scores were classified as follows: 9-15, temporary (nonpathological) anxiety; 16-25, moderate anxiety; and $>25$, severe anxiety. ${ }^{36}$ The Brazilian Portuguese version of the HAMA used in this study was translated and adapted by Freire and colleagues, and was shown to have a Cronbach's alpha in the range of $0.66-0.78$, with $90 \%$ sensitivity and $91 \%$ specificity. ${ }^{37}$ The HAM-A took about 5 min to complete. 


\section{Statistical Analysis}

The data were analyzed in $\mathrm{R}$ software ${ }^{38}$ version 3.4.3. Descriptive analyses for central tendency and dispersion of all analyzed variables were calculated. Data were compared between smokers and non-smokers with Fisher and Wilcoxon post hoc tests. Logistic regression models were elaborated from a set of categories to best characterize suicidal ideation. We used step-wise reduction, the applied Akaike information criterion (AIC), the Bayesian information criterion (BIC), and Chi-square tests to evaluate the models. $^{39}$

For modeling, we assumed a binomial distribution (B) of $Y_{i}$

$$
\mathrm{Y}_{\mathrm{i}} \sim \mathrm{B}\left(\mathrm{n}_{\mathrm{i}}, \pi_{\mathrm{i}}\right)
$$

where $Y_{i}$ is the number of subjects within a group with the target attribute, $n_{i}$ is total the number of subjects in group $\mathrm{i}$, and $\pi_{\mathrm{i}}$ is the probability of a group member having the attribute, as estimated by the regression model. We calculated the $\operatorname{logit}$ of $\pi_{\mathrm{i}}$ as follows:

$$
\operatorname{logit}\left(\pi_{i}\right)=X_{i}^{\prime} \beta
$$

where $X_{i}^{\prime}$ is the vector of the independent variables and $\beta$ is a vector of the regression coefficients.

For all comparative analyses, a significance level of $5 \%$ was utilized. Mean values are reported with standard deviations (SDs). Odds ratios (ORs) for logistic regression modeling are reported with $95 \%$ confidence intervals (CIs).

\section{Results}

\section{Characteristics Of The Cohort}

Table 1 summarizes the overall characteristics of the cohort composed of 988 participants (438 females and 550 males). The mean age of the study participants was $13.5 \pm 1.96$ years. The grade and public versus private school attendance distributions of the participants (for all, females, and males). A large majority of the participants attended public school (377 in municipal elementary schools and 501 in state schools).

The distributions of tobacco addiction levels (for all, females, and males) are reported in Table 1 . The mean age of the smokers $(15.0 \pm 1.6$ years $)$ was higher than that of the non-smokers $(13.0 \pm 1.8$ years; $p<0.0001)$. The portions of boys $(136 / 550,24.7 \%)$ and girls $(107 / 438$, $24.4 \%)$ that were smokers were similar $(p>0.05)$. Notably, students from public schools were more likely to be smokers (including 173/501, 34.5\% attending state public schools; 49/377, 13.0\% attending municipal public schools) than students attending private schools, and students who had experienced 3 years of retention were more likely to be smokers than students who had held back 2 years or less (Table 2). The rates for students that were held back 1 year $(74 / 318 ; 23.3 \%)$ or 2 years $(38 / 151$, $25.2 \%$ ) were intermediate between the two extremes of a 0 -year and 3-year lag, but closer to that of kids who had never been held back $(p>0.05)$.

We observed a general trend toward greater smoking in higher-grade adolescents, with about a tenth of fifth graders in the cohort being smokers and more than a third of eighth and ninth graders being smokers. The most common age band for tobacco experimentation was 14-15 years, at which time experimentation with smoking was twice as likely as that at $12-13$ years of age, three times as likely as that at $\geq 16$ year's age, and six times as likely as that at 11 years old. Overall, most of the adolescents were living in nonsmoking households (Table 2); among those with smoking parents, most had both parents smoking and having only a smoking father was more common than only a smoking mother. Adolescents with at least one smoking parent were more likely to be smokers themselves than adolescents with only non-smoking parents (Table 2).

\section{Relationship Between Anxiety Symptoms, Smoking, And Gender}

Smokers had a higher mean HAM-A score $(21.1 \pm 9.73)$ than non-smokers $(15.4 \pm 8.6 ; p<0.001)$. Correspondingly, students who exhibited indicators of anxiety (HAM-A test score $>16$ ) were at a heightened possibility of being a smoker.

\section{Depression Symptoms, Smoking Status, And Gender}

As summarized in Table 3, overall, relative to non-smokers, smokers had higher total CDI2 scores $(p=0.033)$, as well as higher scores on the Negative Self-esteem, Emotional Problems, and Functional Problems domains of the CD12. Therefore, CDI results showed that females were significantly more likely than males to have depressive symptoms.

\section{Suicidal Ideation, Smoking Status, And Gender}

A logistic regression model that was elaborated from a set of categories, the BIC, and the AIC indicated that the 
Table I Study Participant Characteristics

\begin{tabular}{|c|c|c|c|c|}
\hline Variable & & Total, N Of 988 (\%) & Females, N Of 438 (\%) & Males, N Of 550 (\%) \\
\hline \multirow[t]{2}{*}{ Type of school } & Private & $110(11.1)$ & $80(18.3)$ & $30(5.5)$ \\
\hline & Public & $878(88.9)$ & $358(81.7)$ & $520(94.5)$ \\
\hline \multirow[t]{6}{*}{ School grade (years) } & $\leq 4$ th & $66(6.7)$ & $23(5.3)$ & $43(7.8)$ \\
\hline & 5 th & $312(31.6)$ & $|4|(32.2)$ & $171(31.1)$ \\
\hline & 6th & $51(5.2)$ & $14(3.2)$ & $37(6.7)$ \\
\hline & 7 th & $107(10.8)$ & 51 (II.6) & $56(10.2)$ \\
\hline & 8th & $214(21.7)$ & $107(24.4)$ & $107(19.5)$ \\
\hline & 9th & $238(24.1)$ & $102(23.3)$ & $136(24.7)$ \\
\hline \multirow[t]{4}{*}{ Grade retention (in years) } & 0 & $406(4 I . I)$ & $211(48.2)$ & $195(35.5)$ \\
\hline & 1 & $318(32.2)$ & $137(3 \mid .3)$ & I8I (32.9) \\
\hline & 2 & $151(15.3)$ & $50(11.4)$ & $101(18.4)$ \\
\hline & 3 & $113(11.4)$ & $40(9.1)$ & $73(13.3)$ \\
\hline \multirow[t]{5}{*}{ Socioeconomic level } & $A$ & $10(1)$ & $2(0.5)$ & $8(1.5)$ \\
\hline & B & $472(47.8)$ & $195(44.5)$ & $277(50.4)$ \\
\hline & C & $304(30.8)$ & 144 (32.9) & $160(29.1)$ \\
\hline & $\mathrm{D}$ & $149(15.1)$ & 71 (16.2) & $78(14.2)$ \\
\hline & $E$ & $53(5.4)$ & $26(5.9)$ & $27(4.9)$ \\
\hline \multirow[t]{2}{*}{ Students employed } & No & $919(93)$ & $428(97.7)$ & 491 (89.3) \\
\hline & Yes & $69(7)$ & $10(2.3)$ & $59(10.7)$ \\
\hline \multirow[t]{2}{*}{ Using medication } & No & $928(93.9)$ & $405(92.5)$ & $523(95.1)$ \\
\hline & Yes & $60(6.1)$ & $33(7.5)$ & $27(4.9)$ \\
\hline \multirow[t]{3}{*}{ Diseases } & None & $750(75.9)$ & 315 (7I.9) & $435(79.1)$ \\
\hline & Breathing problems & $221(22.4)$ & II 4 (26) & $107(19.5)$ \\
\hline & Others & $17(1.7)$ & $9(2.1)$ & $8(1.5)$ \\
\hline \multirow[t]{2}{*}{ Smoker } & No & 748 (75.7) & $331(75.6)$ & $417(75.8)$ \\
\hline & Yes & $240(24.3)$ & $107(24.4)$ & $133(24.2)$ \\
\hline \multirow[t]{4}{*}{ Nicotine addiction (FTND) } & Level I-2 & $165(69)$ & $82(77.4)$ & $83(62.4)$ \\
\hline & Level 3 & $57(23.8)$ & $19(16.9)$ & $38(28.6)$ \\
\hline & Level 4 & $6(2.5)$ & I (I) & $6(4.5)$ \\
\hline & Level 5 & II (4.6) & $5(4.7)$ & $6(4.5)$ \\
\hline \multirow[t]{2}{*}{ Serious smoking (FTND) } & No & $924(93.5)$ & $405(92.5)$ & $519(94.4)$ \\
\hline & Yes & $64(6.5)$ & $33(7.5)$ & $31(5.6)$ \\
\hline \multicolumn{5}{|l|}{ Parent information } \\
\hline \multirow[t]{4}{*}{ Father's schooling } & $<$ Fundamental & $107(10.8)$ & $44(10)$ & $63(11.5)$ \\
\hline & Fundamental & $528(53.4)$ & $213(48.6)$ & $315(57.3)$ \\
\hline & Medium & $160(16.2)$ & $86(19.6)$ & $74(13.5)$ \\
\hline & Superior & $193(19.5)$ & $95(21.7)$ & $98(17.8)$ \\
\hline \multirow[t]{4}{*}{ Mother's schooling } & $<$ Fundamental & $57(5.8)$ & $32(7.3)$ & $25(4.5)$ \\
\hline & Fundamental & $567(57.4)$ & $222(50.7)$ & $345(62.7)$ \\
\hline & Medium & $165(16.7)$ & $85(19.4)$ & $80(14.5)$ \\
\hline & Superior & $199(20.1)$ & $99(22.6)$ & $100(18.2)$ \\
\hline \multirow[t]{2}{*}{ Smoking parents } & No & $653(66.1)$ & $298(68)$ & $355(64.5)$ \\
\hline & Yes & $335(33.9)$ & $140(32)$ & $195(35.5)$ \\
\hline \multirow[t]{2}{*}{ Other addictions } & No & 878 (88.9) & $390(89)$ & 488 (88.7) \\
\hline & Yes & $110(11.1)$ & $48(\mathrm{II})$ & 62 (II.3) \\
\hline
\end{tabular}


Table 2 Comparison Of Variables Between Smokers And Non-Smokers

\begin{tabular}{|c|c|c|c|c|}
\hline Variable & Total, N Of 988 (\%) & Smokers, N Of 240 (\%) & Non-Smokers, N Of 748 (\%) & $\mathbf{P}$ \\
\hline Sex (female) & $438(44.3)$ & $107(44.6)$ & $331(44.3)$ & 0.941 \\
\hline Type of school (public) & $878(88.9)$ & $222(92.5)$ & $656(87.7)$ & 0.045 \\
\hline School grade ( $\geq 8$ th) & $452(45.7)$ & $164(68.3)$ & $288(38.5)$ & $<0.001 *$ \\
\hline Grade retention ( $\geq 3$ years) & $113(11.4)$ & $47(19.6)$ & $66(8.8)$ & $<0.001 *$ \\
\hline Father's schooling (<fundamental) & $107(10.8)$ & $41(17.1)$ & $66(8.8)$ & $<0.001 *$ \\
\hline Mother's schooling (<fundamental) & $57(5.8)$ & $25(10.4)$ & $32(4.3)$ & 0.001 \\
\hline Socioeconomic level $(A+B)$ & $482(48.8)$ & $128(53.3)$ & $354(47.3)$ & 0.119 \\
\hline Employed & $69(7.0)$ & $49(20.4)$ & $20(2.7)$ & $<0.001 *$ \\
\hline Using Medication & $60(6.1)$ & $14(5.8)$ & $46(6.1)$ & $>0.999$ \\
\hline Smoking parent(s) & 335 (33.9) & $138(57.5)$ & $197(26.3)$ & $<0.001 *$ \\
\hline Other addictions & $110(1 \mathrm{I} . \mathrm{I})$ & $71(29.6)$ & $39(5.2)$ & $<0.001 *$ \\
\hline
\end{tabular}

Note: Data are $n(\%), *$ Results are significative at $p<0.05$.

occurrence of suicidal ideation was about twice as likely (OR, 2.05; 95\% CI, 1.51-2.80) among participants who were smokers than among those who were non-smokers. Furthermore, female smokers had a substantially greater chance (OR, 1.81; 95\% CI, 1.38-2.37) of suicidal ideation than male smokers.

\section{Discussion}

The present results show a significant association of smoking with depressive symptoms and anxiety symptoms, with an effect of gender as well as an interaction of smoking with suicidal ideation on depressive symptoms in Brazilian youth. We also found evidence of a strong link between smoking and poor school performance (i.e., 3 years of grade retention), consistent with studies in other countries. . $^{12,20,40,41}$

Our findings of public school students being more apt to smoke than private school students and there being a peak of experimenting with smoking at 14-15 years old are somewhat consistent with those of Silva et al, ${ }^{42}$ who showed a positive relationship between later, relative to earlier, adolescence and percentage of students who had experimented with smoking as well as a reduced risk of smoking among private school students. The present results are consistent with recent studies conducted in Thailand, ${ }^{43}$ Peru, ${ }^{44}$ and Canada ${ }^{45}$ in showing that cigarette smoking was associated with depression and suicidal ideation and/or suicide attempts, ${ }^{43-45}$ as well as with studies showing that self-reported dissatisfaction with general life and depression correlated with smoking. ${ }^{10}$ Similar to our findings, previous reports also correlated suicidal behavior with tobacco consumption among adolescents. ${ }^{46,47}$ The present results indicating that females had more depressive symptoms and that female smokers were more likely to experience suicidal ideation than males are consistent with the findings of several studies reporting that female

Table 3 Comparison Of Anxiety Symptoms And Depressive Symptoms Between Smokers And Non-Smokers

\begin{tabular}{|l|l|l|l|l|}
\hline \multirow{2}{*}{ Assessment } & \multicolumn{2}{l|}{ N (\%) } & \multirow{2}{l|}{} \\
\cline { 2 - 5 } & Total N = 988 & Smokers N = 240 & Non-Smokers N = 748 \\
\hline CDI2 & & & & \\
TOTAL SCORE & $389(39.4)$ & $109(45.4)$ & $280(37.4)$ & $0.033^{*}$ \\
EMOTIONAL PROBLEMS & $398(40.3)$ & $112(46.7)$ & $286(38.2)$ & $0.023^{*}$ \\
Negative Mood/Physical Symptoms & $345(34.9)$ & $95(39.6)$ & $250(33.4)$ & 0.087 \\
Negative Self-esteem & $352(35.6)$ & $108(45.0)$ & $244(32.6)$ & $<0.00 I^{*}$ \\
FUNCTIONAL PROBLEMS & $362(36.6)$ & $101(42.1)$ & $261(34.9)$ & $0.046^{*}$ \\
Ineffectiveness & $306(31.0)$ & $76(31.7)$ & $245(32.8)$ & 0.810 \\
Interpersonal Problems & $335(33.9)$ & $90(37.5)$ & $335(68.2)$ & 0.183 \\
HAM-A TOTAL SCORE & & $156(31.8)$ & $<0.00 I^{*}$ \\
\hline
\end{tabular}

Note: Data are $n(\%)$; ${ }^{*}$ Results are significative at $p<0.05$.

Abbreviations: HAM-A, Hamilton Anxiety Rating scale; CDI2, Children Depression Inventory. 
adolescents, especially female adolescent smokers, tend to exhibit more depressive symptoms than their male counterparts. $^{44,48,49}$

Low-level anxiety symptoms (HAM-A score, 9-15) were very common in our total cohort, among both smokers and non-smokers. However, moderate anxiety symptoms (HAM-A score) ${ }^{18,25,45}$ were more prevalent among smokers than non-smokers. Our finding of higher HAM-A scores in smokers than in nonsmokers fits with prior work showing that high emotionality and the presence of stressors were strong determinants of smoking behavior. ${ }^{46}$ Notably, stressful life events have been reported to be more strongly related to the initiation of smoking in women than in men. ${ }^{47}$

Our study also demonstrated that females were prone to a negative mood, consistent with previous work suggesting that negative mood variance may confer an elevated risk of progression to smoking in females. ${ }^{36,49}$ Interestingly, although depression symptoms may be more common in adolescent females than males, depression together with irritable mood has been found to be more common in males. ${ }^{50}$ Overall, our results suggest that a global negative mood may be a gender-biased risk factor for smoking in female adolescents.

It has been suggested that elevated use of tobacco and other drugs in adolescents with anxiety and depression symptoms may be related to the substances' mood elevating and anxiolytic effects. ${ }^{10}$ If true, depressed smokers may smoke to alleviate negative feelings. Indeed, adolescents have related smoking onset with feelings of anxiety, depression, or stress. ${ }^{51,52}$ Although, we cannot make conclusions about the causality or directionality of smoking and emotional state interactions in our study, our findings are not inconsistent with the notion that adolescents may smoke to cope with emotional issues that could be related to the subsequent development of mental disorders. Further exploration of the possibility that smoking risk and depression risk may share genetic psychosocial risk factors is warranted. ${ }^{51}$

Beyond short-term increasing effects on dopamine and serotonin levels in the brain, ${ }^{53}$ nicotine's actions may include dysregulation of the hypothalamic-pituitary-adrenal system, which could lead to hypersecretion of cortisol, a physiological mediator of stress responses. ${ }^{53}$ The molecular biological actions of the many constituents of cigarettes are not known. Additionally, potential epigenetic interactions with smoking should be explored.
Researchers have suggested previously that there may be a synergistic mechanism by which smoking effects on serotonergic network regulation may influence suicidal behavior in individuals with aggressive behavior. ${ }^{54,55}$ Here, we found a disturbingly high percentage of adolescent smokers who experienced suicidal ideation. Suicide among adolescents is a potentially preventable public health issue. Therefore, it is important to identify probable correlates to inform the initiation of interventions. In Brazil, cigarettes are inexpensive and readily available to adolescents. Perhaps, Brazil should invest more in campaigns that improve awareness of this public health issue.

This study had several limitations. First, we analyzed questionnaire responses without clinical diagnoses, evaluation of other drugs used (e.g. cannabis), or assessment of participants' view of the social desirability of smoking. Second, as noted above, the present analyses do not allow us to determine the directionality of the relationship of smoking with anxiety or depression symptoms. Third, we did not investigate the percentage of adolescent smokers who actually attempted suicide. Nonetheless, the prevalence of suicidal ideation observed is concerning given that suicidal ideation has been linked to suicide attempts. ${ }^{56}$

\section{Conclusion}

The present study provides evidence of an association of cigarette smoking with depression and anxiety symptoms, poor school performance, and suicidal ideation in adolescents, with females exhibiting more depressive symptoms and suicidal ideation than males. These results may contribute to the development of anti-smoking strategies for Brazilian youth.

\section{Acknowledgments}

We thank the adolescents and their parents for participating in the study. This study was funded in part by the Secretaria Ciência e Tecnologia e Ensino Superior do Estado do Parana (Conv\#007/14) to MLC. This study was also financed in part by the Coordenação de Aperfeiçoamento de Pessoal de Nivel Superior -Brazil (CAPES) - Finance Code 001.

\section{Author Contributions}

FS and MLC designed the study results. FS completed the field data collection. GP and TBS performed the statistical analyses. MLC and TBS have contributed with relevant literature, interpretations of the results, and did all final corrections. All authors contributed to data analysis, 
drafting, approved the final version of the manuscript, and agree to be accountable for all aspects of the work.

\section{Data Sharing Statement}

All data are available upon direct request from FS (fm.slomp@gmail.com).

\section{Disclosure}

The authors report no conflicts of interest in this work.

\section{References}

1. Giedd JN, Keshavan M, Paus T. Why do many psychiatric disorders emerge during adolescence? Nat Rev Neurosci. 2008;9(12):947-957. doi: $10.1038 / \mathrm{nrn} 2513$

2. Arain M, Haque M, Sharma S, et al. Maturation of the adolescent brain. Neuropsychiatr Dis Treat. 2013;449. doi:10.2147/NDT. S39776.

3. Chassin L, Presson CC, Pitts SC, Sherman SJ. The natural history of cigarette smoking from adolescence to adulthood in a midwestern community sample: multiple trajectories and their psychosocial correlates. Heal Psychol. 2000;19(3):223-231. doi:10.1037/02786133.19.3.223

4. Low NCP, Dugas E, O’Loughlin E, et al. Common stressful life events and difficulties are associated with mental health symptoms and substance use in young adolescents. BMC Psychiatry. 2012;12 (1):1. doi:10.1186/1471-244X-12-116

5. Saari AJ, Kentala J, Mattila KJ. Weaker self-esteem in adolescence predicts smoking. Biomed Res Int. 2015;2015:1-5. doi:10.1155/2015/ 687541

6. Hallfors DD, Waller MW, Ford CA, Halpern CT, Brodish PH, Iritani B. Adolescent depression and suicide risk: association with sex and drug behavior. Am J Prev Med. 2004;27(3):224-231. doi:10.1016/j. amepre.2004.06.001

7. Bonilha AG, Ruffino-Netto A, Sicchieri MP, Achcar JA, RodriguesJúnior AL, Baddini-Martinez J. Correlates of experimentation with smoking and current cigarette consumption among adolescents. $J$ Bras Pneumol. 2014;40(6):634-642. doi:10.1590/S1806-37132014000600007

8. Hill KG, Hawkins JD, Catalano RF, Abbott RD, Guo J. Family influences on the risk of daily smoking initiation. $J$ Adolesc Health. 2005;37(3):202-210. doi:10.1016/j.jadohealth.2004.08.014

9. Fluharty M, Taylor AE, Grabski M, Munafò MR. The association of cigarette smoking with depression and anxiety: a systematic review. Nicotine Tob Res. 2017;19(1):3-13. doi:10.1093/ntr/ntw140

10. Bılg1 B, Aksoy UM, Ö ŞO, Maner AF. Attention-deficit/hyperactivity disorder and nicotine dependence in adults. Noropsikiyatri Ars. 2017;54(4):322-327. doi:10.5152/npa.2017.15882

11. Rissanen T, Viinamäki H, Honkalampi K, et al. Long term life dissatisfaction and subsequent major depressive disorder and poor mental health. BMC Psychiatry. 2011;11. doi:10.1186/1471-244X-11-140

12. Talati A, Wickramaratne PJ, Keyes KM, Hasin DS, Levin FR, Weissman MM. Smoking and psychopathology increasingly associated in recent birth cohorts. Drug Alcohol Depend. 2013;133 (2):724-732. doi:10.1016/j.drugalcdep.2013.08.025

13. Beal SJ, Negriff S, Dorn LD, Pabst S, Schulenberg J. Longitudinal associations between smoking and depressive symptoms among adolescent girls. Prev Sci. 2014;15(4):506-515. doi:10.1007/s11121-0130402-x

14. Taylor AE, Fluharty ME, Bjørngaard JH, et al. Investigating the possible causal association of smoking with depression and anxiety using Mendelian randomisation meta-analysis: the CARTA consortium. BMJ Open. 2014;4:10. doi:10.1136/bmjopen-2014-006141
15. Vieira PC, Aerts DRGDC, Freddo SL, Bittencourt A, Monteiro L. Uso de álcool, tabaco e outras drogas por adolescentes escolares em município do Sul do Brasil. Cad Saude Publica. 2008;24(11):24872498. doi:10.1590/S0102-311X2008001100004

16. Breet E, Goldstone D, Bantjes J. Substance use and suicidal ideation and behaviour in low- and middle-income countries: A systematic review. BMC Public Health. 2018;18(1):1-18. doi:10.1186/s12889018-5425-6

17. Wünsch Filho V, Mirra AP, López RVM, Antunes LF. Tobacco smoking and cancer in Brazil: evidence and prospects. Rev Bras Epidemiol. 2010;13(2):175-187. doi:10.1590/S1415-790X2010000200001

18. Petroianu A, Reis DCFD, Cunha BDS, Souza DMD. Prevalence of alcohol, tobacco and psychotropic drug use among medical students at the Universidade Federal de Minas Gerais. Rev Assoc Med Bras. 2010;56(5):568-571.

19. Barbosa Filho VC, De CW, Lopes ADS. Prevalence of alcohol and tobacco use among Brazilian adolescents : a systematic review. Rev Saúde Pública. 2012;46(5):901-917. doi:10.1590/S0034-89102012000 500018

20. Da Silva Pinto D, Ribeiro SA. Variáveis relacionadas à iniciação do tabagismo entre estudantes do ensino médio de escola pública e particular na cidade de Belém - PA. J Bras Pneumol. 2007;33 (5):558-564. doi:10.1590/S1806-37132007000500011

21. Arrais Ribeiro GL, Clementino MA, Cesarino Gomes MDN, Firmino RT, Lins Dantas Siqueira MB, Granville-Garcia AF. Smoking, behavioral factors and familial environment: a population based study with Brazilian adolescents. Rev Salud Pública. 2013;15(3):342-353. doi:10.15446/rsap

22. Menezes AHR, Dalmas JC, Scarinci IC, Maciel SM, Cardelli AAM. Fatores associados ao uso regular de cigarros por adolescentes estudantes de escolas públicas de Londrina, Paraná, Brasil. Cad Saude Publica. 2014;30(4):774-784. doi:10.1590/0102-311X00173412

23. Lopes FL, Nascimento I, Zin WA, et al. Smoking and psychiatric disorders: a comorbidity survey. Brazilian J Med Biol Res. 2002;35 (8):961-967. doi:10.1590/S0100-879X2002000800013

24. Pawlina MMC, Rondina RDC, Espinosa MM, Botelho C. Nicotine dependence and levels of depression and anxiety in smokers in the process of smoking cessation. Rev Psiquiatr Clin. 2014;41(4):101105. doi:10.1590/0101-60830000000020

25. Prochaska JJ, Das S, Young-Wolff KC. Smoking, mental illness, and public health. Annu Rev Public Health. 2017;38(1):165-185. doi:10.1146/annurev-publhealth-031816-044618

26. Patton GC, Carlin JB, Coffey C, Wolfe R, Hibbert M, Bowes G. Depression, anxiety, and smoking initiation: a prospective study over 3 years. Am J Public Health. 1998;88(10):1518-1522. doi:10.2105/ ajph.88.10.1518

27. Carvajal SC, Granillo TM. A prospective test of distal and proximal determinants of smoking initiation in early adolescents. Addict Behav. 2006;31(4):649-660. doi:10.1016/j.addbeh.2005.05.047

28. Moylan S, Jacka FN, Pasco JA, Berk M. How cigarette smoking may increase the risk of anxiety symptoms and anxiety disorders: a critical review of biological pathways. Brain Behav. 2013;3(3):302-326. doi:10.1002/brb3.137

29. Green M, Turner S, Sareen J. Smoking and suicide: biological and social evidence and causal mechanisms. J Epidemiol Community Health. 2017;71(9):839-840. doi:10.1136/jech-2016-207731

30. Evins AE, Korhonen T, Kinnunen TH, Kaprio J. Prospective association between tobacco smoking and death by suicide: a competing risks hazard analysis in a large twin cohort with 35-year follow-up. Psychol Med. 2017;47(12):2143-2154. doi:10.1017/S0033291717000587

31. Chaplin TM, Aldao A. Gender differences in emotion expression in children: a meta-analytic review. Psychol Bull. 2013;139(4):735-765. doi:10.1037/a0030737

32. Fagerström KO. Measuring degree of physical dependence to tobacco smoking with reference to individualization of treatment. Addict Behav. 1978;3(3-4):235-241. doi:10.1016/0306-4603(78)90024-2 
33. Carmo JD, Pueyo AA. A adaptação para português do Fagerström test for nicotine dependence (FTND) para avaliar a dependência e tolerância à nicotina em fumantes brasileiros. Rev Bras Med. 2002;59:73-80.

34. Kovács M, Staff MHS. The Children's Depression Inventory. 2 (CDI2). Technical Manual. Multi-Health Syst Inc; 2011:157

35. Gouveia V, Barbosa G, Almeida H, Gaião A. Inventário de Depressão Infantil - CDI: estudo de adaptação com escolares de João Pessoa. J Bras Psiq. 1995;44:345-349.

36. Hamilton M. The assessment of anxiey states by rating. $\mathrm{Br} \mathrm{J} \mathrm{Med}$ Psychol. 1959;32:50-55. doi:10.1111/j.2044-8341.1959.tb00467.x

37. Freire MÁ, Figueiredo VLMD, Gomide A, et al. Escala Hamilton: estudo das características psicométricas em uma amostra do sul do Brasil. J Bras Psiquiatr. 2014;63(4):281-289. doi:10.1590/00472085000000036

38. R Core Team. ${ }^{*} \mathrm{R}$ : a language and environment for statistical computing. R Found Stat Comput. 2015.

39. McCullagh P, Nelder JA. Generalized Linear Models. CRC Press; 1989:101-105.

40. Samet J, Yoo S. Women and the Tobacco Epidemic: Challenges for the 21st Century. World Heal Organ; 2001:1-234.

41. Oh DL, Heck JE, Dresler C, et al. Determinants of smoking initiation among women in five European countries: a cross-sectional survey. BMC Public Health. 2010;10:74. doi:10.1186/14712458-10-74

42. Silva MAMD, Rivera IR, Carvalho ACC, Guerra Júnior ADH, Moreira TCDA. The prevalence of and variables associated with smoking in children and adolescents in the Maceió education system. J Pediatr (Rio J). 2006;82(5):365-370. doi:10.2223/ JPED. 1525

43. Pengpid S, Peltzer K, Puckpinyo A. Conjoint moderate or high-risk alcohol and tobacco use among male out-patients in Thailand. South African J Psychiatry. 2016;22(1):nopagination. doi:10.4102/sajpsychiatry.v22i1.763

44. Sharma B, Nam EW, Kim HY, Kim JK. Factors associated with suicidal ideation and suicide attempt among school-going urban adolescents in Peru. Int J Environ Res Public Health. 2015;12 (11):14842-14856. doi:10.3390/ijerph121114842

45. Sampasa-Kanyinga H, Dupuis LC, Ray R. Prevalence and correlates of suicidal ideation and attempts among children and adolescents. Int J Adolesc Med Health. 2017;29(2). doi:10.1515/ijamh-2015-0053
46. Zarrouq B, Bendaou B, Elkinany S, et al. Suicidal behaviors among Moroccan school students: prevalence and association with sociodemographic characteristics and psychoactive substances use: a crosssectional study. BMC Psychiatry. 2015;15(1):1-9. doi:10.1186/ s12888-015-0680-x

47. Ziaei R, Viitasara E, Soares J, et al. Suicidal ideation and its correlates among high school students in Iran: a cross-sectional study. BMC Psychiatry. 2017;17(1):1-7. doi:10.1186/s12888-017-1298-y

48. Lorenzo-Blanco EI, Bares C, Delva J. Correlates of Chilean adolescents' negative attitudes toward cigarettes: the role of gender, peer, parental, and environmental factors. Nicotine Tob Res. 2012;14 (2):142-152. doi: $10.1093 / \mathrm{ntr} / \mathrm{ntr} 152$

49. Bares CB. Gender, depressive symptoms, and daily cigarette use. J Dual Diagn. 2014;10(4):187-196. doi:10.1080/15504263.2014.961852

50. Daniza Ivanovic M, Carmen Castro G, Rodolfo Ivanovic M. Factores que inciden en el habito de fumar de escolares de educación basica y media del Chile. Rev Saude Publica. 1997;31(1):30-43. doi:10.1590/ S0034-89101997000100006

51. Booker CL, Unger JB, Azen SP, Baezconde-Garbanati L, Lickel B, Johnson CA. A longitudinal analysis of stressful life events, smoking behaviors, and gender differences in a multicultural sample of adolescents. Subst Use Misuse. 2008;43(11):1521-1543. doi:10.1080/ 10826080802238009

52. Byrne DG, Mazanov J. Adolescent stress and future smoking behaviour: a prospective investigation. J Psychosom Res. 2003;54(4):313321. doi:10.1016/S0022-3999(02)00411-7

53. Stringaris A, Maughan B, Copeland WS, Costello EJ, Angold A. Irritable mood as a symptom of depression in youth: prevalence, developmental, and clinical correlates in the Great Smoky mountains study. J Am Acad Child Adolesc Psychiatry. 2013;52(8):831-840. doi:10.1016/j.jaac.2013.05.017

54. Windle M, Windle RC. Depressive symptoms and cigarette smoking among middle adolescents: prospective associations and intrapersonal and interpersonal influences. J Consult Clin Psychol. 2001;69 (2):215-226. doi:10.1037/0022-006X.69.2.215

55. Khairani O, Norazua R, Zaiton A. Prevalence and reasons for smoking among upper secondary schoolboys in Hulu Langat, Malaysia. Med Health. 2007;2(21):80-85.

56. Smith SM, Vale WW. The role of the hypothalamic-pituitary-adrenal axis in neuroendocrine responses to stress. Dialogues Clin Neurosci. 2006;8(4):383-395. doi:10.1038/nrendo.2011.222
Neuropsychiatric Disease and Treatment

\section{Publish your work in this journal}

Neuropsychiatric Disease and Treatment is an international, peerreviewed journal of clinical therapeutics and pharmacology focusing on concise rapid reporting of clinical or pre-clinical studies on a range of neuropsychiatric and neurological disorders. This journal is indexed on PubMed Central, the 'PsycINFO' database and CAS, and is the official journal of The International Neuropsychiatric Association (INA). The manuscript management system is completely online and includes a very quick and fair peer-review system, which is all easy to use. Visit http://www.dovepress.com/testimonials.php to read real quotes from published authors. 